\title{
Advocacy for the human rights of older people in the COVID pandemic and beyond: a call to mental health professionals
}

\section{Introduction}

In 2020, COVID-19 hit the earth like a comet. The ground that it seared was already pockmarked by systematic violations of human rights of older people (Doron et al., 2004; Mantovani et al., 2018) particularly those with mental disorders, due to advanced age, frailty, cognitive impairment, multiple mental and physical comorbidities, and social isolation, the so-called multiple jeopardies for disadvantage (Peisah et al., 2011). Ageist and mentalist (i.e. discrimination based on mental illness) assumptions have long-fed unequal treatment, segregation, and discrimination of this group (Quinn et al., 2019).

The ethical debate during the pandemic has focused on biological vulnerability and higher fatality of older people (Applegate and Ouslander, 2020; Ruan, 2020), societal responses of distributive justice, and specifically, ventilator allocation (Truog et al., 2020). There has been relative silence regarding the myriad other human rights issues at stake. The pandemic has brought to the fore longstanding unaddressed gaps in the actualization of older persons' human rights, especially those in residential care (Meenan et al., 2016).

Health care has been notoriously silent about human rights issues and often demonstrates little awareness of human rights frameworks (Byrnes, 2020; Peisah and Jessop, 2020). Now is the time to speak up and act. This commentary is a call to health professionals, particularly those working in geriatric psychiatry, to embrace human rights frameworks as standards of accountability and advocacy in relation to older persons with mental disorders or dementia, whether living in their own homes or in residential care. From the perspectives of a geriatric psychiatrist and international human rights scholars, we outline existing and emerging human rights frameworks and the effects of COVID on this background human rights landscape. We conclude with practical and tangible strategies for health care professionals working in geriatric psychiatry to promote the equal enjoyment of human rights of older persons.

\section{The background human rights landscape}

The rights of persons with disabilities, given more explicit treatment under international law than the rights of older persons, have much relevance to this context. The lack of equal enjoyment of human rights by people with disability and the need for more specificity in generally worded rights guarantees led to the adoption of the United Nations Convention on the Rights of Persons with Disabilities (CRPD). All States that have ratified the CRPD have binding legal obligations under it including under Article 25.d the obligation to ensure that health care professionals provide health care of the same quality to persons with disabilities as to others on the basis of equality.

The key ideas underpinning the CRPD are equality, autonomy, and independence. Of its 50 Articles, the most salient for geriatric psychiatry are:

(1) Article 12: Equal recognition before the law including the right to equal legal capacity, support in exercising that capacity, expression of will and preferences, and the right to be safeguarded against undue influence and abuse;

(2) Article 14: Liberty and security of the person;

(3) Article 16: Freedom from exploitation, violence, and abuse;

(4) Article 19: Living independently and being included in the community;

(5) Article 22: Respect for privacy;

(6) Article 23: Respect for home and family, and relationships; and

(7) Article 25: Enjoyment of the highest attainable standard of health without discrimination, including respecting specific needs that arise on account of disability. Health care professionals are required to provide care of the same quality provided to others on the basis of free and informed consent, calling for a human rights-based practice of health care based on equity of access, autonomy, and dignity.

Existing rights under CRPD as they apply to aged care have not been adequately implemented, nor are rights under other human rights treaties (Dorn and Apter, 2020). These failures have been driven by ageism, systemic inertia, and failure to recognize the specific situations of older persons (Byrnes, 2020; Doron and Apter, 2020). Advocates for a new UN human rights treaty recognize that while existing human rights treaties including CRPD provide important protections, they do not explicitly engage with issues that are of particular relevance to older persons 
(Byrnes, 2020; Doron and Apter, 2020; Doron and Ithaka, 2015; Herro and Byrnes, 2020; UN Human Rights Council, 2018).

Furthermore, a large "implementation gap" has existed between articulation of human rights principles in human rights frameworks, policies and legal instruments, and the actual enjoyment of such (Biggs and Haapala, 2013). On the ground in pre-COVID aged care, equity, autonomy, respect for will and preferences, and specific needs conferred by disability remained aspirational. In Australia and elsewhere, COVID-19 has exploded on a background of longstanding neglect of both community and residential care sectors (Royal Commission, 2017). PreCOVID, social ageism has meant that in the face of resource limitations and recession, service provision in aged and dementia care has suffered most (Biggs and Haapala, 2013).

Steel et al. (2019) argued that segregation of people with dementia in residential care facilities, frequently under duress and involving confinement, represented violations in regards to support for independent community living (Article 19), nondiscrimination (Article 5), liberty and security of the person (Article 14), equality before the law (Article 12), and accessibility (Article 9). Additionally, quality of end-of-life care in such settings has been variable with much of the shortfall involving key human rights of dignity, autonomy, and equitable access to care (Froggatt et al., 2020; PACE, 2019). This has been driven by variable care staff competencies in palliative care due to resource limitations impacting staff education and training (Froggatt et al., 2020). Additionally, respect for autonomy and honoring will and preferences at end of life have been unachievable goals in many aged care settings struggling to implement advance care planning (Gilissen et al., 2020), despite pushes for this dating back some 25 years.

\section{The effect of the COVID-19 pandemic}

These struggles for actualization of older persons' basic human rights have come to the fore in the COVID pandemic. At the extreme, the revelations of appalling numbers of deaths in residential facilities (BBC News, 2020) show failures of policy and practice in ensuring human rights to life and health, among others. At the same time, in some countries, deaths in such facilities literally "didn't count" in mortality figures. The default option of segregating older persons has exposed the heightened vulnerability of congregated settings, where it is intrinsically difficult to secure an adequate standard of health and social distancing (EEG, 2020; Sterling, 2020). It also re-emphasized the fact that despite attempts to transform the institutional landscape of residential care for older persons, it still lacks a true, human rights-based culture (Meenan et al., 2016).

In the absence of equitable triage systems for people living in nursing homes with Coronavirus infection, this status has constituted a death sentence for many. Notably, the Office for Civil Rights, US Department of Health and Human Services (DHHS) recently required the State of Pennsylvania to revise its Interim Pennsylvania Crisis Standards of Care for Pandemic Guidelines to ensure that persons with disability are not discriminated against. Removing criteria that automatically deprioritize persons with disability, these guidelines mandate individualized assessments based on the best available, relevant, and objective medical evidence to support triaging decisions and stipulate that no one be denied care based on stereotypes, assessments of quality of life, or judgments about a person's "worth" based on disability (HHS.gov, 2020).

Numbers of deaths are not all that matters either. In the "tsunami of suffering," equitable access to quality dying has gone by the wayside (Radbruch et al., 2020). Access to essential palliative care and support from loved ones during dying have all been severely curtailed, if not blocked in the face of high demands on health systems. Additionally, the costs in terms of resources, of nuanced support for autonomy and giving voice to will and preferences at the end of life, have also been prohibitive beyond blanket policies of getting people "signed up" as soon as possible with advance care plans. This has culminated in precipitous and sometimes non-competent advance care planning undertaken with older people and their families who have not had opportunities to discuss and reflect on wishes and preferences for end-of-life decisions (Lapid et al., 2020). This has been further complicated by impaired cognition and delirium associated with COVID-19 or other incidental illnesses in older people which affect capacity, as well as missed opportunities for supported decision-making in such circumstances (Peisah et al., 2013).

In an already compromised setting where shortfalls in equitable access to the highest standard of health existed at the outset, it is not surprising that health care delivery has been inconsistent and sporadic when it occurs, with resources diverted to and focused on the acute hospital sector (EEG, 2020; Lacobucci, 2020). In an under-resourced sector, the costs involved in taking on extra staff, dealing with sickness and providing adequate personal protective equipment (PPE), are likely to be prohibitive of quality care (Lacobucci, 2020). This extends beyond the care setting to shortfalls in care provision for older people with mental illness - particularly 
those with severe mental illness or dementia living in the community (Killapsy, 2020).

Similar resource limitations have precluded a nuanced approach to enforcing social distancing while maintaining social connection and relationships. The pandemic has necessitated a difficult balance between best practices for infection control in residential facilities and rights and autonomy of the people who live in them. The problem from a policy-making perspective has been that crisisdriven decision-making regarding infection control, when divorced from an understanding of the historical staffing challenges and care practices of these facilities, has put residents at greater risk. Many countries enforced outright prohibitions on visitation by families and friends of residents as an effort to curtail spread (CMS, 2020), although an earlier, more flexible approach involved screening, social distancing, and allowance of visiting on compassionate grounds (WHO, 2020).

One the one hand, the failure to police the flexible approach, and on the other hand, the blanket exclusions have taken their toll. The restrictive prohibition of visitation enforced without any respect for autonomy or consent from older persons themselves or their loved ones has had a disastrous effect on the mental health and well-being of older people who, in segregated settings where loneliness abounds (Freedman and Nicolle, 2020; Jeste et al., 2020), depend on visits from family and friends for solace and support. At the same time, physical health depends on infection control. In facilities with long histories of understaffing, health, and safety violations, it was often family members who first identified poor hygiene, lack of feeding and hydration, and improper medication management (Sciacca, 2020). The fault lines in the aged care system have opened up.

It takes extra staff and resourcing to ensure that a spouse can safely visit their partner in a nursing home or even stay with them while they are dying. A blanket rule of no visiting is far more cost effective and keeps numbers of deaths down, but not invariably so. Ironically, it has not been family visitors that have brought the infection into care facilities, but staff. Around the world, despite restrictions on visitors through front doors of facilities, the virus quickly came through the back, carried by health care workers forced by low wages to work at multiple facilities simultaneously with insufficient PPE (Read, 2020). The confluence of these events has taken a terrible toll, leaving residents sick and dying alone - sometimes abandoned altogether by the care facilities in which they lived (ABC7 News, 2020).

These violations go hand in hand with a preCOVID global propensity for ageism, which has reared its head in some sections of the community.
This has been borne out in arguments about who has the better claim to emergency medical treatment, whether the economic and social lockdowns and exit strategies have given excessive weight to interests of older cohorts at the expense of younger cohorts and whether intergenerational justice means that younger cohorts will be bearing an unfair proportion of the very large economic costs of the responses to the pandemic.

\section{Recommendations for advocacy by health care professionals}

Health care professionals are well-placed to support human rights of older people at the coalface. Moreover, it is our experience that framing clinical interventions with reference to human rights sometimes causes policy makers or organizations to stop and take notice. We suggest that when human rights inform medical decision-making, that this be explicitly documented in clinical notes. We highlight potential opportunities in everyday medical decision-making (Kayess, 2020) and clinical practice for advocacy:

1. Reference human rights such as rights to equitable access to health, autonomy, and relationships when planning or writing policies or guidelines for health care services, both hospital and community-based, and care facilities;

2. Highlight the importance of autonomy, free and informed consent, supported decision-making, and respect for will and preferences when delivering treatment. Ensure that human rights-based principles of capacity determination are pursued, including but not limited to: (i) presumption of capacity unless there is evidence to rebut that presumption; (ii) capacity is not diagnosis-bound (e.g. based solely on diagnoses of dementia or schizophrenia) (O’Neill and Peisah, 2019; Peisah, 2017);

3. Rigorous and respectful pursuit of will and preferences with authentic advance care planning that is not driven merely by outcomes. Mining the opportunity for the COVID pandemic to increase death literacy in the population and advance care planning in the future (Lapid, 2020);

4. Understanding human rights violations that underpin changed behaviors in dementia with regard to unmet need, will, and preferences (Articles 12 and 25) (Empowered, 2019) arising from social isolation and unmet intimacy. Raising awareness amongst care staff that the right to social connection (Article 23) is as important, if not more so than daily showering, which some people with dementia find distressing and refuse anyway (Farrell-Miller, 1997);

5. Advocating for the right to autonomy and consent with regard to segregation of older people. This might involve actively supporting a family member to connect with, or visit an older person knowing and 
understanding the risks, or bringing an older person home to live during the pandemic (EEG, 2020);

6. Explicitly reference human rights when doing assessments and writing medicolegal reports, such as for applications for guardianship or protection/ administration;

7. Adopting an anti-ageist culture, climate, and daily behavior based on an awareness of existing stereotypes and prejudices against older persons. Policies should ensure that older persons are not categorized or treated solely through the lens of their chronological age (Ayalon, 2020);

8. Ensure rights of older persons to meaningfully participate not only in personal health care decisionmaking but also in shaping broader, macro-level health care policies regarding their rights in residential care settings during times of crisis such as the COVID-19;

9. Triage for emergency care should be based on individualized assessment not on diagnosis or place of residence, consistent with the settlement reached by the US DHHS Office for Civil Rights with Pennsylvania (HHS.gov, 2020).

\section{Conclusion}

In the face of the stressors of the pandemic and without an understanding of human rights, it is easy for health professionals to go "off piste" with regards to human rights, careering down a traditional path of best interests. Certainly, best interests and medical beneficence remain important drivers of medical decision-making (Lapid et al., 2020). However, an understanding of human rights allows us to pursue other equally important goals of autonomy, connectedness, equal treatment, and dignity. Armed with this understanding, it would be a tragic outcome if health professionals missed opportunities for advocacy for the human rights of older people in their everyday clinical work. Moving toward the future, mental health professionals are perfectly placed to join the debate by the UN 1110pen Ended Working Group regarding the possible drafting of a new UN treaty on the rights of older people to pursue the very goals discussed here.

\section{Conflict of interest}

None.

\section{Description of authors' roles}

All authors contributed significantly to the conceptualization and writing of the manuscript.
Carmelle Peisah, ${ }^{1,2,3}$ (i) Andrew Byrnes, ${ }^{4}$ IsRael (Issi) DORON, ${ }^{5}$ (i) Michael DARK ${ }^{6}$ AND GERARD QUINN $^{7,8}$

${ }^{1}$ School of Psychiatry and the Ageing Futures Institute, University of New South Wales (UNSW), Australia

${ }^{2}$ Sydney University, Sydney, Australia

${ }^{3}$ Capacity Australia, Sydney, Australia

${ }^{4}$ Faculty of Law and Ageing Futures Institute, UNSW, Australia

${ }^{5}$ Center for Research and Study of Ageing, Department of Gerontology, University of Haifa, Haifa, Israel

${ }^{6}$ California Advocates for Nursing Home Reform, San

Francisco, CA, USA

${ }^{7}$ Raoul Wallenberg Institute, Lund, Sweden

${ }^{8}$ Leeds University, UK

Email: cpeisah62@bigpond.com

\section{References}

ABC7 News Coronavirus. (2020). 84 residents evacuated from Southern California nursing home after employees do not show up for work [Online]. 9 April. Available at: https://abc7news.com/coronavirus-riverside-countynursing-home-senior-magnolia-rehabilitation-and-center/ 6086909/; last accessed 30 April 2020.

Applegate, W. B. and Ouslander, J. G. (2020). COVID-19 presents high risk to older persons. Fournal of the American Geriatrics Society, 68, 681.

Ayalon, L. (2020). There is nothing new under the sun: ageism and intergenerational tension in the age of the COVID-19 outbreak. International Psychogeriatrics, 1-4. doi:10.1017/ S1041610220000575 [published online ahead of print].

BBC News. (2020). Coronavirus: Spanish army finds care home residents 'dead and abandoned' [Online]. 24 March. Available at: https://www.bbc.co.uk/news/amp/worldeurope-52014023.

Biggs, S. and Haapala, I. (2013). Elder mistreatment ageism and human rights. International Psychogeriatrics, 25, 1299-1306.

Byrnes, A. (2020). Human rights unbound: an unrepentant call for a more complete application of human rights in relation to older persons - and beyond. Australasian fournal on Ageing, 1-8. doi:10.1111/ajag.12800 [published online ahead of print].

CMS Centers for Medicare and Medicaid Services, Center for Clinical Standards and Quality/Quality, Safety \& Oversight Group. (2020). Guidance for infection control and prevention of Coronavirus Disease 2019 (COVID-19) in nursing homes [Online]. 13 March. Available at: https:/www.cms.gov/files/document/3-132020-nursing-home-guidance-covid-19.pdf; last accessed 30 April 2020.

CRPD. United Nations. (2006). Convention on the rights of persons with disabilities [Online]. United Nations: Office of the High Commissioner, Human Rights. Available at: https:/www.ohchr.org/EN/HRBodies/CRPD/Pages/ ConventionRightsPersonsWithDisabilities.aspx; last accessed 30 April 2020. 
Doron, I. (2004). Ageing in the shadow of law: elder guardianship in Israel. Fournal of Ageing and Social Policy, 16(4), 59-77.

Doron, I. and Apter, I. (2010). The debate around the need for an international convention on the rights of older persons. The Gerontologist, 50(5), 586-593.

Doron, I. (2015). Ithaka: On the journey to a new international human rights convention for the rights of older persons. In: R. Ruebner, T. Do and A. Taylor (Eds.), International and Comparative Law on the Rights of Older Persons (pp. 18-34). Lake Mary, FL: Vandeplas Publishing.

EEG. (2020). European Expert Group on transition from institutional to community based care. COVID-19 crisis: People living in institutions must not be written off [Online]. Available at: https://deinstitutionalisation.com/ 2020/04/24/covid-19-crisis-people-living-in-institutionsmust-not-be-written-off/; last accessed 30 April 2020.

Empowered. (2019). 10 essential facts about changed behaviour and psychological symptoms in dementia [Online]. Capacity Australia. Available at: https:// empoweredproject.org.au/wp-content/uploads/2019/08/ Empowered-Project-10-Essential-Facts.pdf; last accessed 30 April 2020.

Farrell Miller, M. (1997). Physical aggressive resident behavior during hygienic care. Fournal of Gerontological Nursing, 23(5), 24-39.

Freedman, A. and Nicolle, J. (2020). Social isolation and loneliness: the new geriatric giants: Approach for primary care. Canadian Family Physician, 66(3), 176-182.

Froggatt, K. A., Moore, D. C., Van den Block, L., Ling, J., Payne, S. A. and PACE consortium collaborative authors on behalf of the European Association for Palliative Care. (2020). Palliative care implementation in long-term care facilities: European Association for Palliative Care White Paper. Fournal of the American Medical Directors Association. doi:10.1016/j.jamda.2020.01.009 [published online ahead of print].

Herro, A. and Byrnes, A. (2020). Framing contests over the human rights of older persons. Australian Yearbook of International Law, 38.

Gilissen, J, Pivodic, L, Wendrich-van Dael, A. et al. (2020). Implementing the theory-based advance care planning ACP + programme for nursing homes: study protocol for a cluster randomised controlled trial and process evaluation. BMC Palliative Care, 19(1), 5.

HHS.gov US Department of Health and Human Services. (2020). OCR resolves civil rights complaint against Pennsylvania after it revises its pandemic health care triaging policies to protect against disability discrimination [Online]. 16 April. Available at: https:// www.hhs.gov/about/news/2020/04/16/ocr-resolves-civilrights-complaint-against-pennsylvania-after-it-revises-itspandemic-health-care.html; last accessed 30 April 2020.

Jeste, D. V., Lee, E. E. and Cacioppo, S. (2020). Battling the modern behavioral epidemic of loneliness: suggestions for research and interventions. $\mathcal{F} A M A$ Psychiatry, 77(6), 553-554.

Kayess, R., Davis, M., Scully, J. L. and Byrnes, A. (2020). Human rights under threat from COVID-19? Concerns raised over disability and ethical decisionmaking [Online]. Available at: https://newsroom.unsw.edu .au/news/general/human-rights-under-threat-covid-19concerns-raised-over-disability-and-ethical-decision; last accessed 30 April 2020.

Killapsy, H. (2020). The impact of COVID-19 on people with severe and complex mental health problems. Concerted action needed urgently [Online]. Available at: https://blogs .ucl.ac.uk/mental-health/2020/03/30/the-impact-of-covid19-onpeople-with-severe-and-complex-mental-healthproblems-concerted-actionneeded-urgently/; last accessed 30 April 2020.

Lacobucci, G. (2020). COVID-19: lack of PPE in care homes is risking spread of virus, leaders warn. The BMF, 368, $\mathrm{m} 1280$.

Lapid, M. I., Koopmans, R., Sampson, E. L., Van den Block, L. and Peisah, C. (2020). Providing quality end of life care to older people in the era of COVID-19: perspectives from five countries.

International Psychogeriatrics, 1-8. doi:10.1017/ S1041610220000836 [published online ahead of print].

Mantovani, E., Spanier, B. and Doron, I. (2018). Ageism, human rights and the European Court of Human Rights: a critical analysis of the Carvalho v. Portugal Case. DePaul fournal for Social Fustice, 11(2), 1-14.

Meenan, H., Rees, N. and Doron, I. (Eds.). (2016). Human Rights and Residential Care for Older Persons: International Perspectives on a Right's Culture. London: Routledge.

O'Neill, N. and Peisah, C. (2019). Capacity and the Law. 3rd ed. Australasian Legal Information Institute (AustLII) Communities. Available at: http://austlii.community/ wiki/Books/CapacityAndTheLaw/; last accessed 30 April 2020.

Palliative Care for Older People in Care and Nursing Homes in Europe (PACE) Project. (2019). Palliative care for dignity in old age: addressing the needs of older people in long-term care facilities in Europe [Online]. Available at: http://www.eupace.eu/publication/pacepolicy-recommendations-palliative-care-dignity-old-age; last accessed 30 April 2020.

Peisah, C and Jessop, T. (2020). A human rights response to the Royal Commission. Australian fournal Dementia Care, 9, 1.

Peisah, C., Sorinmadeayo, D., Mitchell, L. and Hertogh, C. (2013). Decisional capacity: towards an inclusionary approach The International Psychogeriatric Association Task Force on Capacity. International Psychogeriatrics, 25(10), 1571-1579.

Peisah, C. (2017). Capacity assessment. In: H. Chiu and K. Shulman (Eds.), Mental Health and Illness Worldwide: Mental Health and Illness of the Elderly. Springer HbMIE.

Peisah, C., O'Neill, N. and Brodaty, H. (2011). Mental health and human rights in the elderly. In: M. Dudley, D. Derrick Silove and F. Gale (Eds.), Mental Health and Human Rights. Oxford: Oxford University Press.

Quinn, G, Gur, A. and Watson J. (2019). Ageism, moral agency and autonomy: getting beyond guardianship in the 21 st century. In: I. Doron and N. Georgantzi (Eds.), Ageing, Ageism and the Law: European Perspectives on the Rights of Older Persons. Elgar Studies in Law and Society.

Radbruch, L., Knaul, F. M., de Lima, L., de Joncheere, C. and Bhadelia, A. (2020). The key role of palliative care 
in response to the COVID-19 tsunami of suffering. The Lancet, 395(10235), 1467-1469. doi:10.1016/S01406736(20)30964-8.

Read, R. (2020). Nursing home staff spread coronavirus to other facilities, CDC finds [Online]. La Times. 18 March. Available at: https://www.latimes.com/world-nation/story/ 2020-03-18/coronavirus-spread-nursing-homes; last accessed 30 April 2020.

Royal Commission into Aged Care Quality and Safety. (2020). Interim Report: Neglect, 31 October 2019, 3 vols. Available at: https://agedcare.royalcommission.gov.au/ publications/Pages/interim-report.aspx); last accessed 30 April 2020.

Ruan, S. (2020). Likelihood of survival of coronavirus disease 2019 (comment, published online). The Lancet Infectious Diseases, 20(6), 630-631. doi:10.1016/S1473-3099(20) 30257-7.

Sciacca, A. (2020). Should California's health-care industry get blanket protection from COVID-19 charges, lawsuits? Daily Democrat. 21 April. Available at: https://www .dailydemocrat.com/2020/04/21/should-states-health-careindustry-get-blanket-protection-from-covid-19-chargeslawsuits/; last accessed 30 April 2020.
Steele, L., Swaffer, K., Phillipson, L. and Fleming, R. (2019). Questioning segregation of people living with dementia in Australia: an international human rights approach to care homes. Laws, 3, 18, doi:10.3390/ laws8030018.

Stirling, C. (2020). Re: COVID-19: control measures must be equitable and inclusive (Letter to Editor). BMF, 368. doi:10.1136/bmj.m1141.

Truog, R. D., Mitchell, C. and Daley, G. Q. (2020). The toughest triage - allocating ventilators in a pandemic. The New England fournal of Medicine, 382, 1973-1975. doi:10.1056/NEJMp2005689.

United Nations Human Rights Council. (2018). Report of the Independent Expert on the human rights of older persons. UN Doc A/HRC/39/50, para 88.

UN. (2020). Policy Brief: Impact of COVID-19 on Older Persons.

WHO. (2020). World Health Organization Infection Prevention and Control Guidance for Long-Term Care Facilities in the Context of COVID-19: Interim Guidance 21 March 2020. Geneva: WHO. 2020. Available at: https://apps.who.int/iris/bitstream/handle/ 10665/331508/WHO-2019-nCoV-IPC_long_term_care2020.1-eng.pdf; last accessed 30 April 2020. 